\title{
Annual Editor Report 2021
}

\author{
Felipe Ramos ${ }^{1}$, Editor-in-Chief
}

\section{INTRODUCTION}

We bring you the 2021 Annual Editor Report from Brazilian Business Review. Our goal is to inform the academic community about the main news and present BBR's annual data. My term as editor-in-chief of BBR has come to an end. I would like to thank the previous editors, especially Fábio Motoki who support me as co-editor during my term. Our next Editor-in-Chief is going to be Talles Vianna Brugni. Talles holds a PhD in Accounting from USP and is currently an Associate Professor at FUCAPE Business School. I deeply admire Talles for the contributions he has made in recent years to Brazilian and international accounting literature. I am sure he will do an excellent job in the coming years as Editor-in-Chief of BBR. I'll supporting BBR as co-editor during Talles's term.

\section{EDITORIAL PROCESS}

BBR's foremost challenge has not changed: it is to attract and publish high-quality academic research in business. We are happy that BBR has attracted lots of attention from the public. As a generalist journal, BBR has a team of associate editors that covers a broad spectrum of the business area. The current team is a mix of very experienced researchers, recognized as references in their areas, and younger professors who have shown a distinguished capacity of conducting high-quality research. We trust this highly qualified editorial board to decide the fate of their assigned manuscripts and curating contents of great interest to the academic community. The results of this strategy are twofold: BBR is one of the most respected and accessed journals in the area in Brazil, and, consequently, authors consider it a potential channel for their high-quality research. 
BBR also has a policy of rotating its editors, including the Editor-in-Chief (EIC). The EIC has a two-year term, after which he becomes a co-editor. This policy ensures that the journal has a smooth transition, preventing the loss of knowledge and any structural breaks on its processes. Associate editors (AEs) are also rotated, refreshing the editorial board and opening space for rising researchers from time to time. Although this renewal process has its costs, its benefits are worth it. It brings a fresh mindset, opening the journal to new ideas and different intellectual viewpoints.

BBR has kept the possibility for authors to suggest potential reviewers to be assigned to their manuscript. There is also an option to recommend the exclusion of potentially conflicted reviewers. Even if the suggestions are not accepted, it helps the AE in selecting qualified reviewers for the paper.

\section{ANNUAL ACTIVITY AND ACCEPTANCE/REJECTION RATES}

Table 1 compares the same period (Jan $1^{\text {st }}$ to Dec $30^{\text {th }}$ ) of 2020 and 2021 in terms of manuscripts received. This year the number of submissions decreased by approximately $6 \%$. We ended the year with 41 accepted papers, a bigger volume than the year 2020. We still have 22\% of the papers submitted in the evaluation process, which represents a potential paper for approval.

Table 1

Manuscripts received 2020-2021

\begin{tabular}{cccccccc}
\hline \multicolumn{7}{c}{ Annual Outcome Summary - By Journal Year Annual Cohort } \\
\hline Year & $\begin{array}{c}\text { New } \\
\text { Submissions } \\
\text { Received } \\
\text { (a) }\end{array}$ & $\begin{array}{c}\text { Number of } \\
\text { Rejections } \\
\text { (b) }\end{array}$ & $\begin{array}{c}\text { Percentage } \\
\text { of Rejections } \\
\text { (c) }=(\mathrm{b}) /(\mathrm{a})\end{array}$ & $\begin{array}{c}\text { Number of } \\
\text { Papers in } \\
\text { Process } \\
\text { (d) }\end{array}$ & $\begin{array}{c}\text { Percentage } \\
\text { in Process } \\
(\mathrm{e})=(\mathrm{d}) /(\mathrm{a})\end{array}$ & $\begin{array}{c}\text { Number of } \\
\text { Acceptances } \\
(\mathrm{f})\end{array}$ & $\begin{array}{c}\text { Percentage of } \\
\text { Acceptances } \\
(\mathrm{g})=(\mathrm{f}) /(\mathrm{a})\end{array}$ \\
\hline 2020 & 205 & 121 & $59 \%$ & 63 & $31 \%$ & 21 & $10 \%$ \\
2021 & 192 & 140 & $73 \%$ & 42 & $22 \%$ & 41 & $21 \%$ \\
\hline
\end{tabular}

Table 2 breaks down the total of manuscript decision letters sent. The major phase of rejection is in the first round, when both the Editor-in-Chief and the Associate Editor conduct the desk review process. At this point of the editorial process, there are two foremost worries: the viability of the research in terms of incremental contribution and adequateness of the method to answer the research question.

The numbers for 2021 are very similar to those presented in 2020. The percentage of papers accepted in the second and third rounds still basically the same as in 2020. This shows that the authors have been able to meet the requests made by the reviewers, as well as the reviewers have recognized the advances made by the authors. This year it still rarer for a paper to be rejected at the third round, just one paper was rejected. Such evidence reinforces the importance of properly responding to the issues contained in the review. 
Table 2

Manuscript decisions - 2021

\begin{tabular}{llrrrr}
\hline Decision Outcomes & & $\mathbf{2 0 2 0}$ & \multicolumn{3}{c}{$\mathbf{2 0 2 1}$} \\
\hline Decision Letter Sent & $\mathbf{2 4 7}$ & & $\mathbf{2 6 0}$ & \\
\hline First-Round Outcomes & & $\mathbf{1 7 3}$ & & $\mathbf{1 9 4}$ & \\
& Accept & 0 & $0 \%$ & 0 & $0 \%$ \\
& Revise \& Resubmit & 50 & $29 \%$ & 57 & $29 \%$ \\
& Reject & 123 & $71 \%$ & 137 & $71 \%$ \\
\hline Second-Round Outcomes & & $\mathbf{4 6}$ & & $\mathbf{4 7}$ & \\
& Accept & 19 & $41 \%$ & 23 & $49 \%$ \\
& Revise \& Resubmit & 23 & $50 \%$ & 20 & $43 \%$ \\
& Reject & 4 & $9 \%$ & 4 & $8 \%$ \\
\hline \multirow{2}{*}{ Third and Later-Round Outcomes } & & $\mathbf{3 2}$ & & $\mathbf{1 9}$ & \\
& Accept & 26 & $81 \%$ & 14 & $74 \%$ \\
& Revise \& Resubmit & 6 & $19 \%$ & 4 & $21 \%$ \\
& Reject & 0 & $0 \%$ & 1 & $5 \%$ \\
\hline
\end{tabular}

\section{PROCESSING TIMES}

BBR's average time between submission and acceptance is about 230 to 280 days. Bear in mind that a perfect first-round takes more than 100 days from submission to $R \& R$, and less than half of the second-rounds go into the third and later rounds. The numbers show that BBR is committed to providing feedback to authors as soon as possible, while still maintaining a high-quality evaluation process.

\section{BBR'S REACH}

The BBR's is indexed by Scopus and we have requested indexing by Web of Science, and we are currently waiting for Clarivate's assessment. These initiatives will expose BBR's articles to a more international audience, and in the long term should leverage both citations and submissions.

Figure 1 displays updated stats from Redalyc. It contains Business Administration \& Accounting journals from Brazil ranked as A2 by the Brazilian Ministry of Education (the same rank as BBR) that are indexed by Redalyc. BBR still has the most article downloads, more than 620,000. Its level of internationalization (lower is better) is still in line with most Brazilian periodicals of the A2 stratum, despite the diversity of authors' countries is lower than most.

About $81 \%$ of the BBR's website traffic came from Brazilian addresses. The remaining 19\% came from several countries, with the second common being the US and the rest from other countries. This diversity corroborates our perception that is of utmost importance that BBR remains a bilingual journal. Figure 2 shows the countries with the most accesses. 
BBR

19

IV

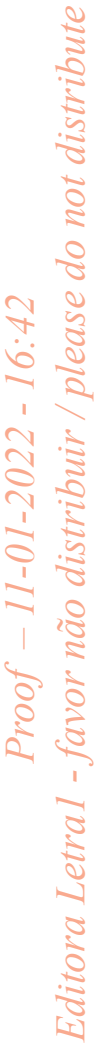

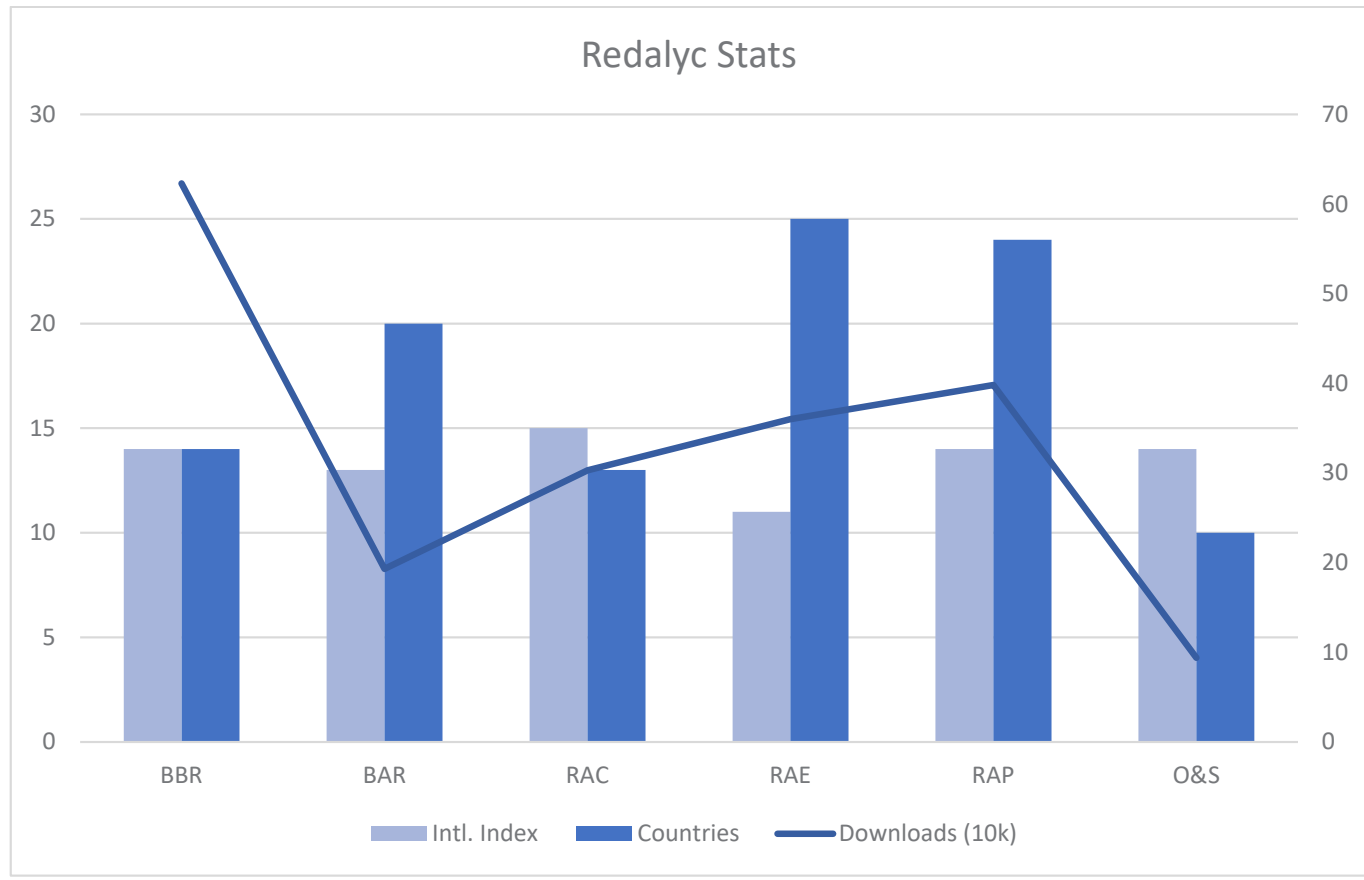

Figure 1. Selected Redalyc stats on Brazilian journals -2020

Notes: BBR is Brazilian Business Review. BAR is Brazilian Administration Review. RAC is Journal of Contemporary Administration. RAE is Journal of Business Management. RAP is Brazilian Journal of Public Administration. O\&S is Organizaçóes \& Sociedade. Intl. Index is a conversion to a decimal scale from 0 (most international) to 24 (least international) of the two-tier classification of Redalyc. Each level goes from 1 to 5 (1 is more international) and measures the diversity of authors' nationalities and how important is the participation of international authors in the journal's published articles (Redalyc, n.d.). For instance, BBR's classification is $3^{5}$, which translates into 14 in the graph. Countries is the number of distinct authors' countries who have published. Downloads is the number of downloads (in tens of thousands, secondary right-hand axis) recorded in Redalyc.

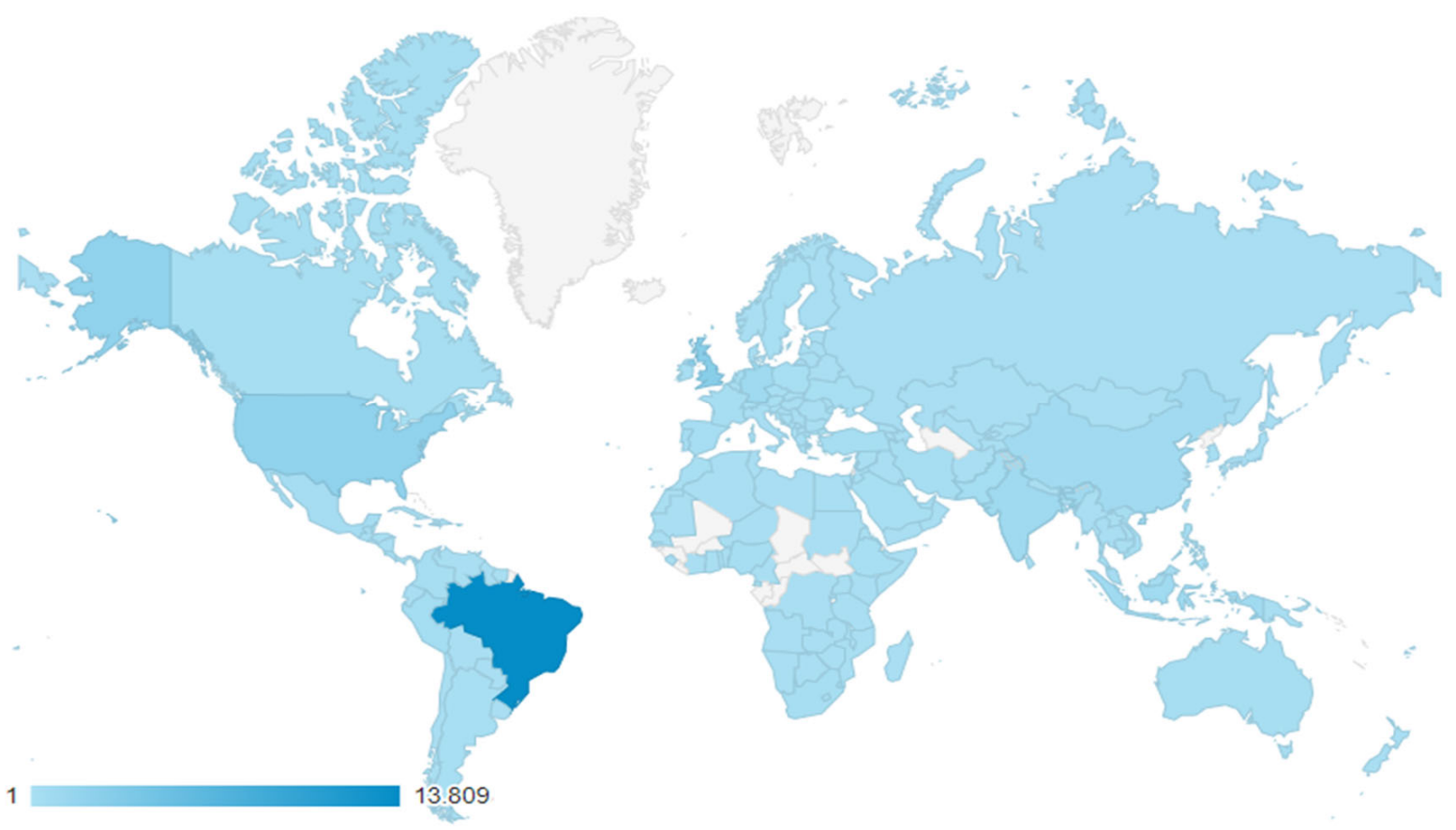

Figure 2. Google Analytics statistics for BBR users. 


\section{ACKNOWLEDGEMENTS}

This year we have had two editorial assistants. Júlia was our editorial assistant from 2020 to mid-2021, always working in a very professional way and contributing a lot to the development of BBR. Laiz has taken over the position in recent months and has been doing an excellent job. We thank both for the seamless transitions, both have done a great job in keeping the editorial process running smoothly. A special thanks to Laiz for accepting the challenge!

Our Associate Editors have kept their deep commitment to BBR. We cannot thank you enough for granting us part of your very precious time and knowledge. I would like to give a special thanks to three associate editors who completed their time at BBR in 2021, Fábio Motoki, Luiz Felipe de Araújo Pontes Giráo and Marcelo de Souza Bispo. They were brilliant in the role of editor bringing great contributions to the journal. We will always be grateful for your dedication.

We also extend our deep thanks to our 147 reviewers of 2021, who also donated these extremely valuable assets to BBR. Constantly the authors praise BBR's smooth evaluation process, and surely our editors, our reviewers, and our editorial assistant are key to this. A roster with all 2021 reviewers follows in Appendix A.

Of course, we cannot forget our authors. We have received many deeply interesting studies, some of them with intriguing themes. The trust you deposit in BBR is heartwarming, helping BBR maintain its position as one of the main Brazilian outlets for high-quality research in business.

We also reaffirm our gratitude to our Supporting Institution, FUCAPE Business School, and $\mathrm{CNPq}$, for providing part of the financial resources needed by BBR.

\section{REFERENCE}

Redalyc. (n.d.). from https://www.redalyc.org. 
Abreu, Welles

Afonso Vieira, Valter

Alano, Carlos

Alves, Fernanda

Alves, Helena

Alves, Murilo

Amaral, António

Anacoreta, Luisa

Andrade de Lima, Mauricio

Andrade, Silveli

Araújo, Rhoberta

Backes, Danieli

Bataglia, Walter

Bellini, Carlo

Benner, Mats

Bido, Diógenes

Binotto, Erlaine

Bitencourt, Claudia

Bitti, Eugenio

Borges, Cândido

Braga, Ana

Braido, Gabriel

Cabral, Lucas

Carvalho, Juliana

Casa Nova, Silvia

Castro Martins, Henrique

Castro, Jose

Chiuzi, Rafael

Cisneros, Juliana

Coelho, Ana Lúcia

Colauto, Romualdo

Corral, Julio

Correia Xavier, Gustavo

Costa Júnior, Júlio

Costa, Cristiano

Crubellate, João Marcelo

Cunha, Jacqueline

Cunha, Julio

d'Angelo, Marcia

Dal-Soto, Fábio

Dalmacio, Flavia

Damajorovic, Jaques

De Andrade, Alexsandro

de Faveri, Diego

de Lima, Francisco de Sousa, Josiano

De Toni, Deonir

Dias, Claudia

Dias, Jorge

dos Santos, Rogiene

Dos-Santos, Marcos

Evangelista Fonseca, Simone

Farias, Josivania

Farinha, Luis

Felix, Bruno

Fernandes, Gabriela

Filho, José

Flores Costa, Vívian

Formiga, Kléber

Formiga, Kléber

Freitas, Flávia

Freitas, Kenyth

Furquim, Nelson

Furtado, Liliane

Gallon, Shalimar

Garcia Lopes, Humberto Elias

Goldszmidt, Rafael

Guerrazzi, Luiz

Haces Atondo, Gerardo

Helal, Diogo

Hernandez-Perlines, Felipe

José, Bruno

Klann, Roberto

Klein, Amarolinda

Kubo, Edson

Laurett, Rozélia

Leal, Fernanda

Lima, Edmilson

Lima, Vinícius

Lopes, João

Lúcio, Fábio

Macedo, João Marcelo

Maciel, Alessandra

Mapanga, Arthur

Marchiori, Danilo

Marques, Carla

Marques, Vagner

Martens, Cristina

Martins, Henrique

Martins, Orleans 
Mauro, Jose

Medeiros, Elvira

Mhlanga, Oswald

Miragaia, Dina

Moll Brandão, Marcelo

Momo, Fernanda

Mota, Renato

Mott, Michel

Moura, Elton

Moura, Ralf

MUCCI, DANIEL

Nassif, Vânia

Neto, Silvio

Nossa, Valcemiro

Nunes, Moema Pereira

Oliveira, Lucia

Paganini, Paulo

Paiva, Kely

Pereira, Breno

Perez, Gilberto

Pimentel, Duarte

Pinto, Marcelo

Prado, Alexsandro

Ramos, Guilherme

reis, germano

Reis, Yuna

Ribeiro, Tarsila

Rocha, Leonardo

Rocha, Thelma
Rodrigues, Evaldo César

Rodrigues, Ricardo

Rosa, Rodrigo

Rossi, George

Santos, Kathyana

VII

Saraiva, Tiago

Schlickmann, Raphael

Semprebon, Elder

Sepulcri, Lara

Silva Jr., Roberto Gregorio

Silva Junior, Claudio Pilar

Silva, Hermes

Silva, Marcos Aurelio

Silva, Minelle

Simic, Mirna

Sousa, Rossana

Souza, José

Tavares, Gustavo

Tureta, César

Urdan, André

varvakis, gregorio

Vasconcelos, Adriana

Veiga, Claudimar

Veites, Yan

Veloso, Andres

Weires, Kelly

Zanandrea, Gabriela

Zaro, Elise 